\title{
Dampak Kehadiran Transportasi Online Terhadap Pendapatan Pengemudi Taksi Kota Konvensional Di Kota Palangka Raya (Studi Kasus Terminal Mihing Manasa)
}

\author{
Arynovebryana Br. Manihuruk ${ }^{1}$, Rinto Alexandro², Sundari ${ }^{3}$, Kuwing Baboe ${ }^{4}$, Tonich Uda ${ }^{5}$ \\ 1* Mahasiswa Program Studi Pendidikan Ekonomi Fa kultas Keguruan dan Ilmu Pendidikan \\ Universitas Palangka Raya \\ 2,3,4,5 Program Studi Pendidikan Ekonomi Fakultas Keguruan da n IImu Pendidikan Universitas Palangka Raya \\ *Corres pondence a uthor: manihurukaryn@gmail.com; Tel.:+6282304463XX
}

\begin{abstract}
Revenue is the amount of input obtained for the services provided by the company which may indude the sale of products and or services to customers obtained in an operating activity of a company to increase the value of assets and reduce liabilities arising in the delivery of goods or services. The purpose of this studyistofind out and describe how the impact of the presence of online transportation on the income of conventional citytaxi drivers in Palangka Raya City. The method used in this research is a qualitative method with descriptive analysis method, namely the researcher is intended to collect data or information about an existing phenomeno $n$. The types of data used are primary data and secondary data. Data collection techniques consisting of observation, interviews and documentation. Data analysis was used using techniques from three stages of activities carried out sequentially, namely reducing data, presenting data, and drawing conclusions. The results of the study indicate that the presence of online transportation in Palangka Raya City has an impact on the income of conventional city taxi drivers, namely a decrease in the income of conventional taxi drivers caused by fare problems, convenience, security and the shift of passenger interest. The existence of online transportationservices in the City of Palangka Raya has an impact on city taxi drivers (angkot), which causes them to experience a reduction in passenger interest.
\end{abstract}

Keywords: Impact, Online Transportation, Conventional Transportation, Income

\begin{abstract}
Abstrak: Pendapatan adalah jumlah ma sukan yang didapat atas ja sa yangdiberikanoleh perusahaanyangbisa meliputi penjualan produk dan a ta u jasa kepada pelanggan yang diperol eh dalamsuatuaktivitas operasi suatu perusahaa n untuk meningkatkan nilai as et serta menurunkan liabilitas yang timbul dalampenyerahan barang atau jasa. Tuj uan dari penelitian ini untuk mengeta hui dan mendeskripsikan bagaimana dampakkehadiran transportasi online terhadap pendapatan pengemudi taksi kota konvensional di Kota Palangka Raya. Metode yang digunakan dalam penelitian adalah metode kualita tif dengan metode analisis des kriptif yaitupeneliti dimaksudkan untuk mengumpulkan da ta ata u informasi mengenai suatu fenomena yang ada.Jenis data yang digunakan adalah data primer dan data sekunder. Teknik pengumpulan data yang terdiri dari observasi, wawancara dan dokumentasi. Analisis da ta digunakan dengan menggunakan teknikdaritigatahapankegiatan yang dilaksanakan seca ra berurutan yai tu mereduksi data, penyajiandata,dan penarikankesimpulan. Darihasil penelitian menunjukkan bahwa ha dirnya transporta si onlinedi Kota Palangka Raya berdampakpada pendapatan pengemudi taksi kota konvensional yaitu terjadinya penurunan penda patanpengemudi taksi konvensionalyang disebabkan oleh permasala han ta rif, kenyamanan, keamanan dan berali hnya minat penumpang. Adanya transportasi online pelayanan di Kota Palangka Raya berdampak terhadap pengemudi taksi kota(angkot),yang menyebabkan mereka mengalami pengurangan minat penumpang.
\end{abstract}

Kata Kunci: Dampak, Transportasi Online, Transportasi Konvensional, Pendapatan 


\section{Pendahuluan}

Kehadiran kendaraan sangatlah penting dalam kehidupan ini, hal ini dikarenakan kendaraan berfungsi untuk membantu proses keberlangsungan hidup manusia sebagai alat transportasi. Meningkatnya kebutuhan masyarakat terhadap angkutan umum menyebabkan penyebara nangkutan di Indonesia kini semakin mengalami peningkatan seiring dengan berjalannya waktu. Permintaan akan adanya angkutan yang dapat dengan cepat tiba ditempat tujuan, serta angkutan yang dapat dengan mudah ditemukan oleh masyarakat sehingga efisiensi waktu dapat lebih optimal. Kebutuhan akan alat juga transportasi sangat dirasakan dalam menunjang mobilitas seseorang setiap harinya, terutama di zaman modern seperti sekarang. Ada berbagai jenis alat transportasi yang bisa dijumpai di zaman sekarang, baik itu yang modern (mobil, motor, pesawat, kereta api,dan lain-lain) atau tradisional (bendi, becak, dan lain-lain). Namun ditengah semakin modernnya alat transportasi, kita masih bisa menjumpai di beberapa daerah di Indonesia yang masih bertahan dengan transportasi tradisional sampai saat ini, salah satunya adalah angkot. Seiring dengan semakin berkembangnya smartphone (telepon pintar) yang memiliki fitur teknologi aplikasi untuk menghubungkan penumpangsmartphone ke internet, mendorong perkembangan teknologi aplikasi hingga akhirnya saat ini dimanfaatkan sebagai media bisnis. Sehingga masyarakat lebih mudah memilih transportasi berbasis aplikasi online sesuai kehendak dan kebutuhannya, yaitu transportasi online. Menurut Hangganararas (2017) "Dengan adanya transportasi online, para penumpang kini tak perlu lagi menghampiri pangkalan ojek, becak ataupun tak perlu lagi menunggu di pinggir jalan untuk mendapatkan taksi. Selain itu, para penumpang juga tidak harus terlibat dalam proses tawar-menawar karena tarif yang sudah ditentukan berdasarkan jarak tempuh. Ketika terjebak kemacetan di jalan, penumpang tidak perlu khawatir mengenai tarif yang membengkak seperti pada saat menaiki transportasi berargometer, karena tarif yang sudah ditentukan diawal perjalanan dengan berdasarkan jarak tempuh. Perubahan gaya hidup inilah yang dimanfaatkan oleh para pelaku usaha untuk memulai persaingan usaha dalam bisnis transportasi online". Palangka Raya sebagai ibu kota dari Kalimantan Tengah, tentu saja memiliki tingkat aktivitas yang cukup tinggi sehingga transportasi umum seperti angkot menjadi pilihan untuk membantu aktivitas warganya sehari-hari. Angkutan kota di Palangka Raya dikenal sebagai angkot atau taksi kota. Angkot atau taksi kota adalah angkutan kota yang disediakan pemerintah untuk menjadi salah satu angkutan umum masyarakat kota Palangka Raya. Angkutan kota atau biasanya disebut taksi kota adalah transportasi yang telah ditentukan arahnya yaitu dari satu tempat ke tempat lain dalam suatu daerah kota dengan menggunakan mobil yang berwarna kuning orange. Angkutan kota (angkot) sekarang eksistensinya di masyarakat menurun, seperti di kota Palangka Raya saat ini hanya sebagian kecil masyarakat yang menggunakannya. Hal ini disebabkan berbagai faktor, salah satunya disebabkan oleh kemajuan zaman yang semakin modern sehingga masyarakat lebih memilih transportasi online karena lebih banyak kemudahan dan lebih cepat sampai tujuan. Akibat hadirnya transportasi online, menyebabkan taksi kota semakin kurang penumpangnya dan itu berdampak terhadap pendapatan pengemudinya. Pendapatan yang semakin berkurang tentu saja akan berpengaruh terhadap perekonomian pengemudi taksi kota (angkot).

\section{Metode}

Penelitian ini meggunakan pendekatan kualitatif denganjenis metode deskriptif. Sugiyono (2016: 09) metode penelitian kualitatif adalah metode penelitian yang berlandaskan pada filsafat postpositivisme, digunakan untuk meneliti pada obyek yang alamiah, (sebagai lawannya adalah eksperimen) dimana peneliti adalah sebagai instrumen kunci, teknik pengumpulan data dilakukan secara triangulasi (gabungan), analisis data bersifat induktif/kualitatif, dan hasil penelitian lebih menekankan makna daripada generalisasi.

Lokasi penelitian ini dilaksanakan di terminal Mihing Manasa J. Letkol Darmosugondo No. 01, Kelurahan Pahandut, Kecamatan Pahandut Kota Palangka Raya Provinsi Kalimantan Tengah, khusus pada pengemudi angkot kota. 
Data primer adalah data yang diperoleh langsung di lokasi penelitian. Data tersebut diperoleh langsung melalui kegiatan observasi dan wawancara peneliti dengan informan. Jumlah informan yang terdapat dalam penelitian ini ada berjumlah 7 informan. Dimana untuk informan daripada taksi kota (angkot) itu sendiri berjumlah 3 informan, sedangkan untuk informan penumpang transportasi baik konvensional ataupun online berjumlah 4 orang.

Data sekunder adalah data yang diperoleh dalam bentuk dokumentasi yang tersusun secara baik mengenai masalah dampak layanan angkutan online.

Teknik pengumpulaan data yang peneliti gunakan adalah:

1. Dokumentasi

Metode ini digunakan dengan menelaah bahasan teoritis dari berbagai buku-buku, jurnal ilmiah, dan karya ilmiah yang berhubungan dengan penulisan.

2. Observasi

Metode ini dilakukan dengan cara turun langsung ke lapangan, untuk melakukan wawancara langsung dengan para informan dan pihak-pihak lain yang mengetahui informasi yang dibutuhkan dalam Penelitian.

\section{Wawancara}

Peneliti memperoleh informasi seputar tanya jawab dengan para pengendara transportasi konvensional, penumpang dan dinas perhubungan.

\section{Analisis Data}

1. Reduksi data (seleksi data), yang prosesnya akan dilakukan sepanjang penelitian berlangsung dan penulisan laporan. Reduksi data merujuk pada proses pemilihan, pemfokusan, penyederhanaan, abstraksi, dan pentransformasian (data mentah) yang terjadi dalam catatan-catatan tertulis.

2. Display data (Sajian Data), dengan berusaha menampilkan data yang akan dikumpulkan nanti.

3. Kesimpulan/verifikasi, dalam hal ini peneliti melakukan atau penarikan kesimpulan.

\section{Hasil dan Pembahasan Hasil Penelitian}

Dari hasil wawancara peneliti dengan Ibu Rosaria Siagian sebagai Kasi Angkutan dalam Trayek Dinas Perhubungan Kota Palangka Raya mengatakan bahwa "Terminal Mihing Manasa sudah berkembang di Kota Palangka Raya sejaktahun 1980-an". Sebelumnya Terminal Mihing Manasa sering berpindah-pindah hingga pada akhirnya sampai saat ini berada di Jl. Letkol Darmosugondo No. 01, Kelurahan Pahandut, Kecamatan Pahandut, Kota Palangka Raya karena dari segi pendapatan taksi kota (angkot) ini tidak boleh jauh dari pasar karena target utama daripa da pengemudi adalah Ibu-ibu yang berbelanja kepasar. Perkembang daripada taksi kota (angkot) ini sendiri menurut Bapak Noor Iwan, S.H selaku Kasi Pengujian Sarana Dinas Perhubungan Kota Palangka Raya mengatakan bahwa sejak dahulu banyak perubahan daripada taksi kota (angkot) ini, dahulu bentuk fisik dari taksi kota (angkot) ini belum seperti sekarang ini, mulai dari jenis kendaraannya, dan juga jurusannya. Kemudian baru diperbaharui pada tahun 1990-an yaitu dengan taksi kota (angkot) jenis saat ini. Dalam hal ini penulis akan menyajikan data observasi, wawancara dan dokumentasi yang sebagaimana penulis peroleh selama berada dilapangan secara langsung. taksi kota yang ada di Kota Palangka Raya dapat disimpulkan bahwa kondisi pengemudi taksi kota (angkot) dapat dilihat dari pendapatan setiap harinya sebelum adanya transportasi online, pendapatan rata-rata yang didapat yaitu sebesar Rp.100.000Rp.150.000, namun setelah adanya transportasi online para pengemudi taksi kota hanya mendapatkan Rp.20.000-Rp.50.000. Dari penjelasan di atas dapat dilihat bahwa kondisi pengemudi taksi kota sangat memprihatinkan dikarenakan pendapatannya yang jauh menurun setelah adanya transportasi online. Ada beberapa faktor yang dapat mempengaruhi pendapatan pengemudi taksi kota yaitu, menurut Nasrullah mengatakan munculnya transportasi online, kemajuan jaman dan Covid-19 sangat berdampak besar bagi mereka pengemudi taksi kota (angkot) sehingga sangat mempengaruhi pendapatan mereka. Dengan berkembangnya teknologi yang semakin canggih hadirlah terobosan baru untuk memudahkan masyarakat yaitu transportasi online yang sedang marak saat ini. Dari keadaan 
tersebut membuat pengemudi taksi kota (angkot) semakin tersaingi dan penumpang lebih memilih menggunakan transportasi online yang lebih memudahkan calon penumpang mendapatkan transportasi hanya menggunakan smartphone tanpa harus keluar rumah. Pekerjaan yang berprofesi sebagai pengemudi taksi kota (angkot) merupakan satu-satunya pekerjaan yang mereka tekuni. Seperti salah satu informan yang bernama Sugianur mengatakan profesi sebagai pengemudi angkot adalah satu-satunya pekerjaan yang mereka lakukan setiap harinya, karena minimnya pendidikan, susahnya mencari pekerjaan, dan minimnya modal untuk membuka usaha sendiri, maka satu-satunya pekerjaan yang mereka tekuni untuk menafkahi keluarganya yaitu dengan menajadi pengemudi taksi kota (angkot).

Dari hasil wawancara yang juga dilakukan peneliti hampir dari seluruh pengemudi taksi kota (angkot) mengatakan bahwa ha dirnya transportasi online sangat berda mpak bagi penda patan mereka, mereka juga mengatakan tidak mau menyalahkan pihak manapun karena sema-sama mencari rezeki. Sebelum kehadiran transportasi online angkot ini memang sudah berkurang penumpangnya namun dengan hadirnya transportasi online semakin membuat pendapatan menjadi minim jika dibandingkan dengan sebelum hadirnya transportasi online. Selain munculnya transportasi online, kemajuan jaman dan Covid-19 juga sangat berdampak besar bagi mereka pengemudi taksi kota (angkot) sehingga sangat mempengaruhi pendapatan mereka. Dengan berkembangnya teknologi yang semakin canggih hadirlah terobosan baru untuk memudahkan masyarakat yaitu transportasi online yang sedang marak saat ini.

Dari hasil pengamatan bahwa kehadiran transpotasi online berdampak terhadap pendapatan pengemudi taksi kota (angkot), hal tersebut terjadi karena merasa bahwa sumber memperoleh uang mereka telah diambil oleh transportasi online.

\section{Pembahasan Penelitian}

Berdasarkan hasil penelitian tentang Dampak Kehadiran Transportasi Online Terhadap Pendapatan Pengemudi Taksi Kota Konvensional Di Kota Palangka Raya (Studi Kasus Terminal Mihing Mahasa). Maka dapat dibahas hasil penelitian yang diperoleh peneliti antara lain sebagai berikut:

1) Dampak pendapatan para pengemudi taksi kota (angkot) di Kota Palangka Raya semenjak hadirnya transportasi online semakin hari semakin menurun dan kebanyakan dari pengemudi taksi kota (angkot) tersebut sering mengeluh karena tarif yang mereka dapatkan hanya bisa untuk mengisi bahan bakar taksi kota (angkot) tersebut, sangat jarang untuk bisa dibawa pulang. Mereka juga kesusahan dalam beroperasi disebabkan minimnya penumpang. Hadirnya transportasi online di Kota Palangka Raya berdampak bagi para pengemudi taksi kota (angkot). Untuk masyarakat Kota Palangka Raya mereka berhak memilih angkutan yang mereka inginkan sesuai dengan tujuan mereka serta tentang kenyaman dan kenyaman. Kecanggihan teknologi saat ini membuat pelaku usaha membuat inovasi untuk memadukan kecanggihan teknologi internet dengan angkutan tansportasi umum yang memudahkan masyarakat untuk mengakses melalui internet agar lebih mudah yang disebut transportasi online. Transportasi online menguasai dan merambat segala titik daerah beroperasi pendapatan dan setoran bersumber dari konsumen langsung adanya online, tempat pangkalan angkutan pusat perbelanjaan dan kampus. Memenuhi kebutuhan hidup merupakan hal yang terasa sangat sulit dilakukan oleh sebagian besar anggota masyarakat jika apa yang mereka hasilkan dari pekerjaan mereka tidak sesuai dengan besarnya kebutuhan yang ingin dipenuhi. Begitupun yang dialami oleh pengemudi taksi kota (angkot) di Kota Palangka Raya. Pemenuhan untuk kebutuhan pokok seperti makan dan minum pun sulit terpenuhi, terlebih dengan kebutuhan lain. Setelah hadirnya transportasi online para pengemudi taksi kota (angkot) semakin kesusahan untuk mencari nafkah dalam melangsungkan hidup mereka. Berpindahnya penumpang dari taksi kota (angkot) ke transportasi online, sangatlah merugikan pihak taksi konvensional. Kesempatan dalam memperoleh pekerjaan yang bisa diandalkan, seperti menjadi pekerja tetap tidaklah mudah, mengingat peluang untuk memperoleh kesempatan tidak sama. Tidak bisa dipungkiri bahwa saat ini, tingkat pendidikan dan keterampilan adalah menjadi modal utama yang menjadi tuntutan dalam persaingan dunia kerja. Hal tersebut yang membatasi mereka dalam memperoleh peluang kerja yang lebih besar. Maka dapat disimpulkan berdasarkan hasil penelitian 
penulis, bahwa kehadiran transportasi online (Gojek) terhadap pendapatan taksi kota (angkot) dapat dikatakan sangat berdampak dan dapat mempengaruhi pendapatan taksi kota (angkot) di karenakan adanya bukti fisik via aplikasi meliputi: pelayanan yang baik, tarif yang flat, kenyamanan, promosi, efesiensi waktu atas kebutuhan pelanggan.

2) Berdasarkan penelitian yang telah peneliti lakukan bahwa hal ini berarti bahwa kehadiran transportasi online di Kota Palangka Raya berpengaruh terhadap pendapatan taksi kota (angkot) di Kota Palangka Raya, karena penumpang yang semakin hari semakin menurun karena hadirnya transportasi online sehingga pendapatannya tidak menentu setiap harinya. Berdasarkan penuturan dari beberapa informan sebelumnya bahwa penghasilan mereka sebelum adanya transportasi online bisa mencapai Rp.100.000-Rp.150.000/hari. Sedangkan setelah hadirnya transportasi online penghasilan mereka turun drastis yaitu menjadi Rp.20.000-Rp.50.000/hari. Dengan pendapatan yang semakin menurun ini mereka dituntut untuk memenuhi kebutuhan hidupnya sehari-hari, hal ini membuat mereka untuk lebih ulek dalam menyiasati keuangan mereka agar semua kebutuhan sehari-hari dapat terpenuhi. Banyaknya kendaraan pribadi masyarakat yang mengurangi minat terhadap taksi kota (angkot), banyaknya unit taksi kota (angkot) yang kurang layak jalan dan lainlain. Menjadi pekerja tetap yang bisa memperoleh pendapatan yang layak merupakan idaman bagi setiap orang dalam memenuhi kebutuhan. Akan tetapi, tingkat pendidikan dan keterampilan sebagai acuan utama dalam memperoleh pekerjaan menjadi penghalang bagi mereka pengemudi taksi kota (angkot), mengingat dari pendidikan terakhir mereka hanya SLTA sederajat.

\section{SIMPULAN}

Berdasarkan hasil penelitian yang dilakukan oleh peneliti terhadap “Dampak Kehadiran Transportasi Online Terhadap Pendapatan Pengemudi Taksi Kota Konvensional Di Kota Palangka Raya (Studi Kasus Terminal Mihing Mahasa)" dapat disimpulkan sebagai berikut: a) Kehadiran Gojek berdampak terhadap pendapatan taksi kota (angkot) di Kota Palangka Raya. Dengan menurunya minat masyarakat yang beralih pada transportasi online sehingga pendapatan yang dihasilkan setiap harinya mengalami penurunan. Berdasarkan hasil wawancara kepada informan pengemudi taksi kota (angkot) terbukti bahwa, rata-rata pendapatan sebelum adanya transportasi online (Gojek) adalah Rp 100.000 - Rp 150.000 per hari, dan setelah hadirnya transportasi online (Gojek) pendapatan menurun dengan kisaran sebesar Rp 20.000 - Rp 50.000 per hari. b) Kehadiran transportasi online di Kota Palangka Raya di terima dengan baik oleh masyarakat, di satu sisi telah memberikan dampak positif bagi masyarakat dalam pemenuhan kebutuhan transportasi yang praktis, aman, nyaman dan murah. Sehingga pemberi jasa taksi kota (angkot) menjadi terbelakangkan oleh keunggulan yang dimiliki transportasi online. c) Berdasarkan penelitian yang dilakukan, kehadiran transportasi online memberikan dampak terhadap jumlah pelanggan pengemudi taksi Kota (angkot). Terbukti bahwa terdapat penurunan jumlah pelanggan taksi Kota (angkot) sebelum dan sesudah hadirnya transportasi online.

\section{Daftar Pustaka}

Al Mukaromah, M., Yuliari, K., \& Arifin, M. 2019. Dampak Keberadaan Transportasi On Line Terhadap Kondisi Sosial Ekonomi Transportasi Konvesional Di Kota Kediri. JIMEK: Jurnal IImiah Mahasiswa Ekonomi, 2(2), 168-181. Diakses pada tanggal 01 Mei 2021

Anwar, A. A. 2017. Online vs konvensional: keunggulan dan konflik antar moda transportasi di kota makassar. ETNOSIA: Jurnal Etnografi Indonesia, 2(2), 220-246. Diakses pada tanggal 03 Mei 2021

Diem Trinh. 2013. Measuring Tourist's Satisfaction With Public Transport In Munich, Germany. Internatinal Journalo Of Business Tourism And Applied Sciences. 1(1): h: 74-83. Diakses pada tanggal 01 Mei 2021 
Donald, E., Jerry, j., \& Terry, D. 2011. Akuntansi Intermediate, Edisi Kedua Belas. Erlangga. Jakarta. Diakses pada tanggal 03 Mei 2021

Erlin, PS. 2016. Hukum Transportasi. https://www.scribd.com/doc/301970778/1-HUKUMTRANSPORTASI-pptx. Diakses pada tanggal 03 Mei 2021

Hangganararas, S. 2017. Analisis Kelayakan Layanan GO-JEK Sebagai Moda Transportasi di Yogyakarta. Yogyakarta: Universitas Atma Jaya.Diakses pada tanggal 27 april 2021

Hans, K, Rosita, U, S, . Merliyana, S, . Sylvia, V, S. (2012). Akuntansi Keuangan berdasarkan SAK berbasis IFRS. Jakarta : Salemba. Diakses pada tanggal 19 Januari 2021

Hariyati, S. 2015. Persepsi Masyarakat Terhadap Pembangunan Jembatan Mahkota li Di Kota Samarinda. Ejournal IImu Pemerintahan, 3(2). Diakses pada tanggal 03 Mei 2021

Hendrayanti, Alberta, J.A, . 2018. Pengaruh Angkutan Umum di Daerah Istimewa Yogyakarta - Fakultas Teknik Universitas Atma Jaya Yogyakart. Diakses pada tanggal 01 Mei 2021

Juliansyah Noor, S. E. 2016. Metodologi Penelitian: Skripsi, Tesis, Disertasi \& Karya Ilmiah. Prenada Media.Diakses pada tanggal 03 Mei 2021

Mangatta, Baihaqi Hendri. 2016. Strategi Adaptasi Tukang Becak dalam Kehidupan Sosial Ekonomi (Studi Kasus Tukang Becak di Kelurahan Bontobiraeng Kecamatan Mamajang Kota Makassar). HOLISTIK, Journal Of Social and Culture. Diakses pada tanggal 19 Januari 2021

Manis, S. 2018. Pengertian Transportasi, Ciri, Unsur, Manfaat, Jenis dan Contoh Transportasi Lengkap. https://www.pelajaran.co.id/2018/02/pengertian-transportasi-ciri-unsur-manfaat-jenis-dancontoh-transportasi-lengkap.html. Diakses pada tanggal 29 april 2021

Moleong, L, J,. 2012. Metodologi Penelitian Kualitatif. Bandung : PT Remaja Rosdakarya.Diakses pada tanggal 28 Januari2021.

Nirmala, N., \& Surveyandini, M. 2019. FAKTOR PENENTU PEMILIHAN JASA TRANSPORTASI ONLINE PADA MASYARAKAT BANYUMAS. Sustainable Competitive Advantage (SCA), 9(1). Diakses pada tanggal 29 april 2021

Prokal, Co. (22 November 2016). Ternyata Jumlah Angkot di Palangka Raya Hanya Tersisa Segini. Kalteng. Diakses pada tanggal 26 Mei 2021

Prokal, Co. (18 Juni 2018). Angkot di Terminal Mihing Manasa Bakal Dipindah. Kalteng. Diakses pada tanggal 26 Mei 2021

Sugiyono. 2016. Metode Penelitian Kuantitatif, Kualitatif, dan R\&D. Bandung: Alfabeta

Umar, H. 2002. Metode Riset Komunikasi Organisasi: sebuah pendekatan kuantitatif, dilengkapi dengan contoh proposal dan hasil riset komunikasi organisasi. Penerbit PT Gramedia Pustaka Utama.Diakses pada tanggal 09 Januari 2021 